\title{
REVISING GREEN \\ INFRASTRUCTURE
}

Concepts Between Nature and Design

Edited by

Daniel Czechowski

Thomas Hauck

Georg Hausladen 


\title{
12 Counterpoint The Musical Analogy, Periodicity, and Rural Urban Dynamics
}

\author{
Matthew Skjonsberg
}

\section{CONTENTS}

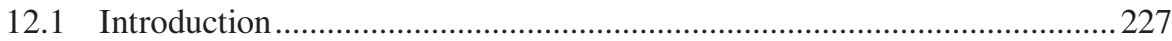

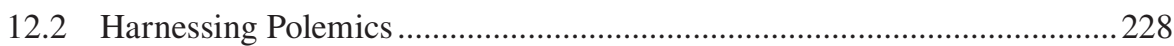

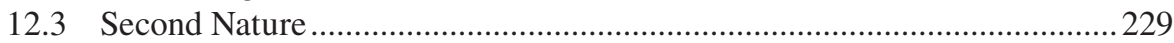

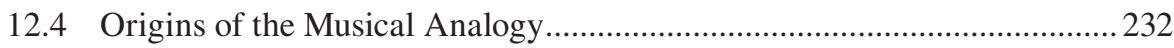

12.5 How to Think Contrapuntally ................................................................... 233

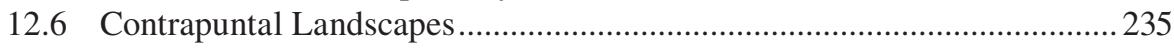

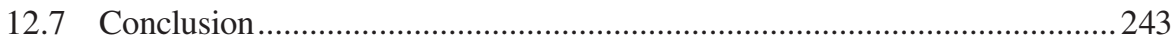

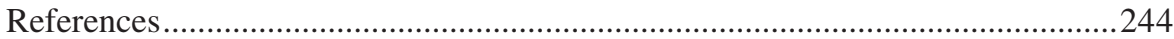

\subsection{INTRODUCTION}

Every thesis calls for its antithesis, and every revolution prompts a counterrevolutionthis takes place within the same generation as well as across intergenerational oscillations (Gassett 1958, Sennett 1974). Enlightenment thinkers were critical of the Humanist tradition of analogical thinking - their own encyclopedic enthusiasm was intent upon creating a lexicon of the world, an ambition that has been assiduously realized in contemporary Geographic Information Systems (GIS) and empirical attitudes toward industrial agriculture and managerial urbanization. However, languages are comprised of two parts-a lexicon and grammar-and analogical thinking, focused as it is on seeing relationships between parts, is particularly well suited to provide conceptual frameworks for contextual design. To harness the power of polemics, we can anticipate that at least two conceptual paradigms, polarities to one another, are needed at any given moment - and that these are best conceived of as, to paraphrase Sébastien Marot, "opposite, but not exclusive of one another" (Marot 2003). Further, as any given analogy will inevitably prompt justifiable reactions against it, I propose that we work between those two oldest and most enduring architectural analogies: the biological analogy (on growth and form) and the musical analogy (on composition and form). Of these, the biological analogy is clearly in ascendancy_see, for example, Philip Steadman's seminal The Evolution 
of Designs: The Biological Analogy in Architecture and the Applied Arts (Steadman 1979, 2008) or Lynn Margulis' The Basic Unit of Life (Margulis 2010). Hence, this sustained reflection on the musical analogy, made with a view to its instrumentality for composing rural urban dynamics in relation to existing landscapes.

\subsection{HARNESSING POLEMICS}

A public event at the Harvard Graduate School of Design commemorating the 50th anniversary of the urban design field featured a discussion between advocates of "New Urbanism" and "Landscape Urbanism." The moderator, Michael Sorkin, concluded the polemic event with the statement, "Let's make humane, equitable, sustainable and beautiful cities ... Cities need to supply their own food, energy, water, thermal behavior, air quality, movement systems, building and cultural and economic institutions. This urban self-sufficiency is a means to political autonomy and planetary responsibility. Sustainable, equitable, and beautiful ..." (Sherman 2010). In staking out this common ground, Sorkin puts his finger on the need for urban designers to be tuned in to their responsibility to champion public interest and engage the public imagination. But it is important to consider whether cities really should be, or even could be, self-sufficient.

Johann Heinrich von Thünen's The Isolated State of 1826 put forth principles relating the "city of commerce" with its rural hinterlands. These principles were illustrated with a simple diagram, as seen in Figure 12.1, representing an idealized central city in an unarticulated field, surrounded by a series of concentric rings defining production zones whose distance from the city is determined by an equation relating key variables: $\mathrm{R}=\mathrm{Y}(\mathrm{p}-\mathrm{c})-\mathrm{Yfm}$, where $\mathrm{R}=$ land rent, $\mathrm{Y}=$ yield per unit of land, $\mathrm{c}=$ production expenses per unit of commodity, $\mathrm{p}=$ market price per unit of commodity, $\mathrm{F}=$ freight rate, and $\mathrm{m}=$ distance to market (von Thünen 1966).

The equation's simplicity supports its utility—advancing the rational principles of a self-sufficient city based on capital and rent, ostensibly conceived of as neutral and objective. But analysis of real, historic capital networks shows that the reach

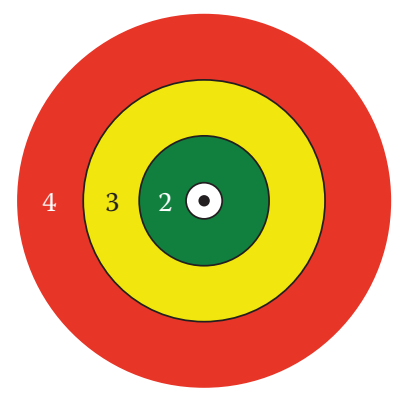

FIGURE 12.1 The isolated state. von Thünen's model: The black dot represents a city; 1 (white) dairy and market gardening; 2 (green) forest for fuel; 3 (yellow) grains and field crops; 4 (red) ranching. The area beyond this represents wilderness where agriculture is not profitable. (Image courtesy of Matthew Skjonsberg, after von Thünen.) 
of the city's economic footprint is much broader and more uneven (Cronon 1991). This "uneven development" was identified by Marx as being a fundamental characteristic of capitalism, leading to the simultaneous emergence of concentrations of wealth and capital on the one hand and poverty and oppression on the other. In extreme cases of "uneven development," short-term economic gains often involve the permanent loss of the very ecologies and social structures on which both rural and urban rely.

In principle, of course, every artificially created thing is only other things rearranged - that is to say, displaced and recomposed. The surface extraction of materials, mining and open pit mining, vividly illustrate the "cut and fill" nature of architecture, infrastructure, and urbanization. It is important that urban designers look to the origins of the resources they work with and acknowledge that the extraction of subterranean resources, such as water, oil, and "natural" gas from distant regions causes geological fractures and leaves substantial underground voids, destabilizing the land above, depleting and poisoning groundwater, and causing sinkholes and earthquakes. Recognition of the importance of urban context must therefore broaden the conceptual scope of urban design.

\subsection{SECOND NATURE}

Since their historic appearance about 10,000 years ago in the Fertile Crescent, the cradle of civilization, urbanization and agriculture have been interrelated. In De Natura Deorum (The Nature of the Gods ca. 45 BC) Cicero coined the term second nature to describe the domain of infrastructure relating urban and rural districts within their regional contexts, writing, “... we sow cereals and plant trees; we irrigate our lands and fertilize them. We fortify riverbanks, and straighten or divert the courses of rivers. In short, by the work of our hands we strive to create a sort of second nature within the world of nature" (Cicero 2008). The fundamental reliance of cities on this designed second nature within a contextual first nature is illuminated by Kostas Terzidis: "In Greek, the word 'design' is schedio, which is derived ... from the word eschein, which is the past tense of the word eho, which ... means to have, hold, or possess. Translating the etymological context into English, it can be said that design is about something we once had, but have no longer" (Terzidis 2007a). This recognition of design as an activity that reveals preexisting qualities and implicit relationships that are neglected, obscured, or forgotten is very different than the idea of invention or stylistic innovation generally associated with design. Terzidis points out that design and planning are terms that, while often conflated, have quite different implications. "Design is about conceptualization, imagination, and interpretation. In contrast, planning is about realization, organization, and execution ... Design provides the spark of an idea and the formation of a mental image" (Terzidis 2007b). These mental images are shaped through the dual processes of analogy and of abstraction by which concepts are derived from the classification of experiences and information. Analogy

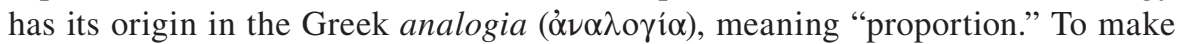
an analogy is a cognitive process by which meaning is transferred from a relatively known subject to one less well known. For instance, in his early work, physicist 
Niels Bohr drew an analogy between the solar system and atomic structure. He developed a model of the atom with the nucleus at the center and electrons in orbit around it, which he compared to the planets orbiting the sun-work for which he subsequently won the Nobel Prize in 1922. Although this analogy is now known to be accurate only in a very limited sense, it provided a useful step in the right conceptual direction.

Contemporary idealization of the city as self-sufficient, on the other hand, abstracts and conceptually isolates the urban from the rural and from those very natural and cultural systems that make the city possible to begin with. In Method in Social Science: A Realist Approach, Andrew Sayer writes, "A bad abstraction arbitrarily divides the indivisible and/or lumps together the unrelated and the inessential, thereby 'carving up' the object of study with little or no regard for its structure and form" (2010). The self-sufficient city-like the idealized, undifferentiated planar surface of von Thünen's The Isolated State-is hardly to be seen in reality. Likewise, the Cartesian grid is prized for its conceptual simplicity as an interscalar system of reference, but as a design framework, at the regional scale, it is hardly capable of responding to the complex topography of mountains and river valleys. One wellestablished model more capable of responding to the complex interactions between rural and urban networks and their sites can be found in computational geometry: the dual network triangulation method of Voronoi diagrams and Delauney triangulation as seen in Figure 12.2.

The Voronoi/Delaunay dual network can be read as a conceptual framework for understanding urban and rural as phases of the same civilizing force, second nature (see Figure 12.3).

Second nature is sited within first nature, and together, these constitute a higherlevel Voronoi/Delaunay dual network. As the notion of these nested geometries can extend to three and higher dimensions, generalizations are possible in metrics other than Euclidean ones, and in principle, they resemble the periodic optimization that is seen in the "nesting" interaction of normal matter and dark matter distributed throughout the universe itself. Quantum physicists even refer to the entire set of the known laws of physics as the "landscape," echoing Bohr's interscalar analogy. Such recurring analogies highlight how the principle of periodicity can inform a conceptual

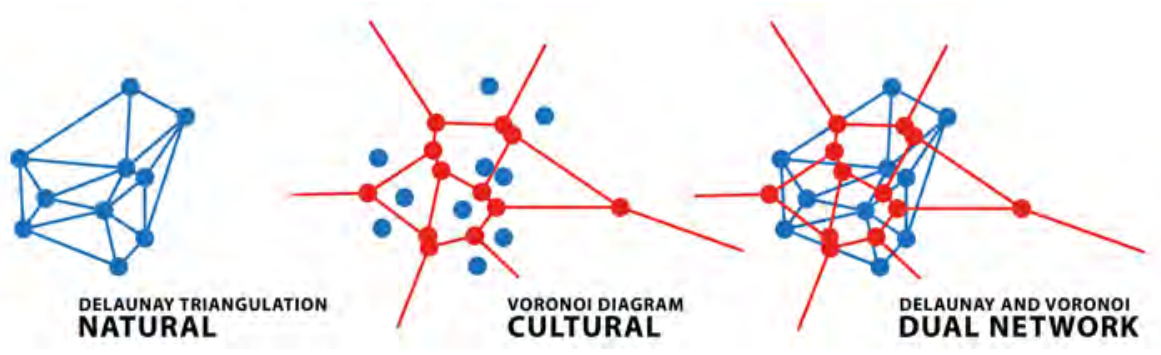

FIGURE 12.2 Dual network. Natural and cultural infrastructural networks are arranged in counterpoint to one another, together forming a dual network as second nature. (Image courtesy of Matthew Skjonsberg.) 


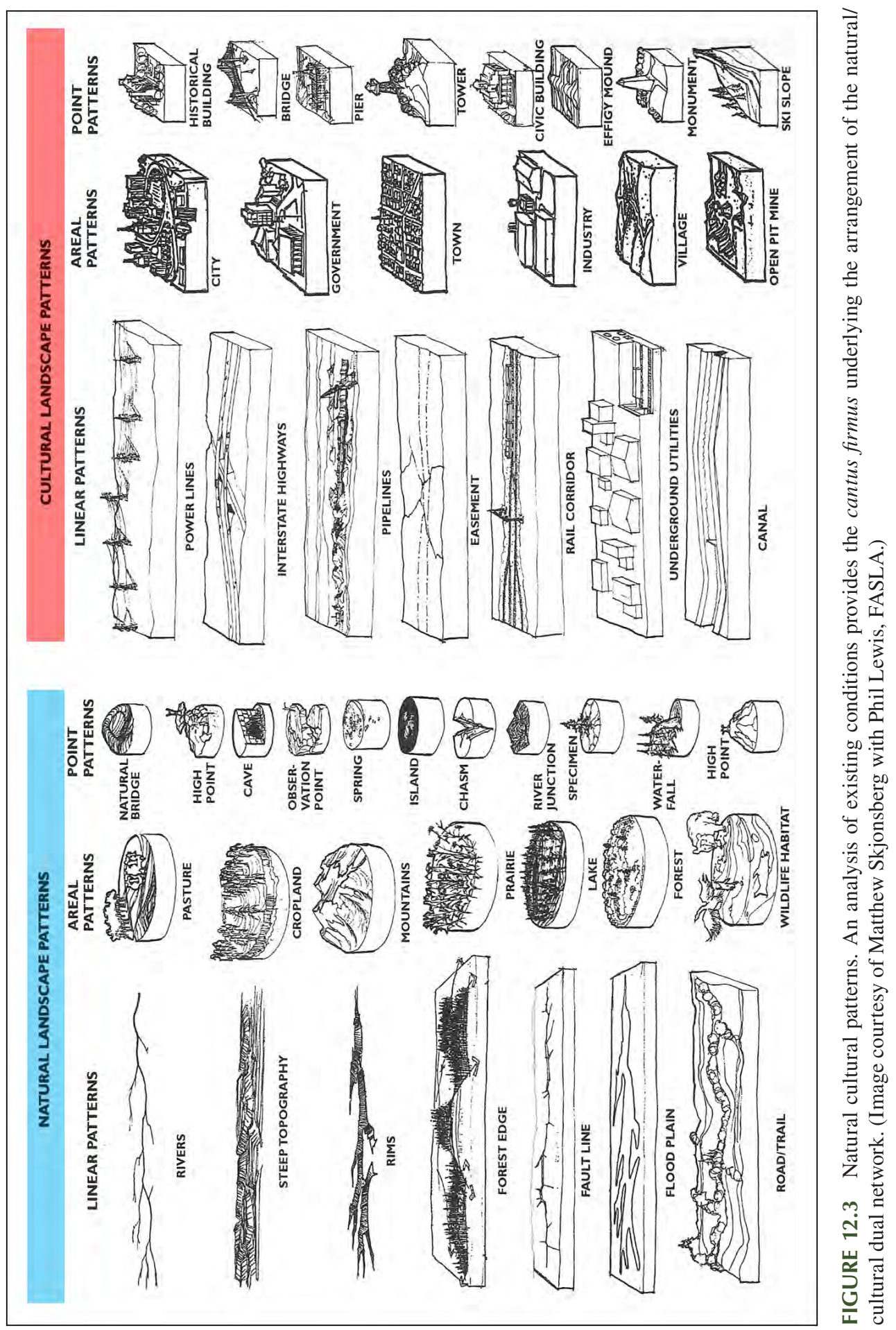


model of design that is both more holistic and more responsive to the underlying ecological and social realities of rural urban dynamics.

\subsection{ORIGINS OF THE MUSICAL ANALOGY}

Music is among the earliest and most enduring of architectural analogies. Following Cicero in the first century B.C., a period in which some of the greatest works of Roman infrastructure were established, the architecture of Vitruvius was largely based on the proportional musical investigations of Pythagoras (570-495 B.C.). In the 15th century, shortly after the rediscovery of Vitruvius, these Pythagorean principles were greeted with renewed enthusiasm. In Chapter VI of his De re aedificatoria (On the Art of Building), Leon Battista Alberti methodically develops the relationship between proportion and architectural form, writing, "We shall therefore borrow all our Rules for the Finishing of our Proportions, from the Musicians, who are the greatest Masters of this Sort of Numbers, and from those Things wherein Nature shows herself most excellent and complete" (1965).

The term contrapunctus, from the Latin punctus contra punctum ("point against point" or "note against note"), initially appeared around 1300. In 1412, the Italian theorist Prosdocimo de Beldomandi wrote that rather than dealing with note against note individually, the composer was actually concerned with the problem of cantus contra cantum - one complete melody against another - thus requiring a new integration of vertical (harmonic) and horizontal (melodic) concepts (de Beldomandi 1984). With this realization, counterpoint gradually came to be recognized in its full complexity, resulting in the "golden age of polyphony" (Fux 1971, vii). It is interesting to note that it was just one year later, in 1413, that architect Filippo Brunelleschi established the geometric method of perspective drawing. Indeed, both counterpoint composition and perspective drawing illustrate the emergence of three-dimensional thinking - the composer dealing with multiple voices in time in a manner very similar to the architect's newly contextual conception of buildings within a multilayered landscape. In both cases, the breakthroughs involved new insights into proportional principles underlying physical reality. In perspective drawing, this was a system of proportions on paper that accurately related to actual sizes and distances, and counterpoint composition addressed resonant harmonic phenomena and the means of engendering it - namely the range of voice or instrument. Beyond being merely picturesque, these developments illustrate the capability of design to derive meaningful order from apparent complexity.

In 1725, the Viennese musician and theorist Johann Fux published Gradus Ad Parnassum, a work that was to set the standard for counterpoint composition to this day. Written in the form of a classical Greek dialogue between an elder master composer and his young apprentice, the lessons are laid out in sequence according to what had by then become the five "species" of counterpoint, from the simplest to the most complex: first species-whole note against whole note; second species —whole note against two half notes; third species-whole note against four quarter notes; fourth species-whole note against syncopated whole note; fifth species-florid counterpoint, using all the previous species. Further, based on sophisticated insights into harmonic phenomena assiduously obtained by the cumulative effort of many 


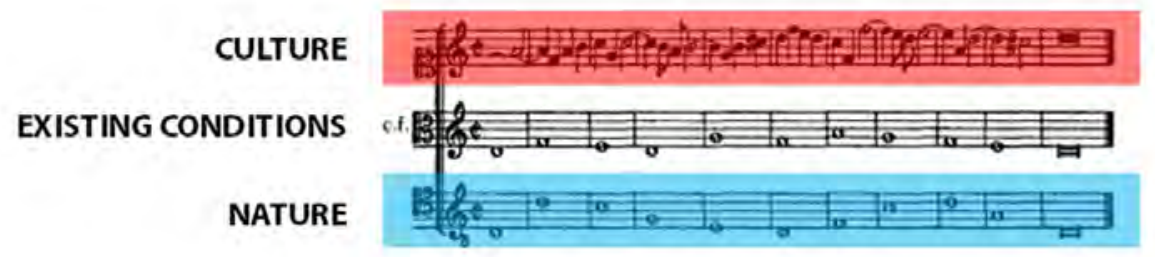

FIGURE 12.4 Musical analogy. The musical analogy is among the most enduring of conceptual models for architecture. Counterpoint compositions begin with the cantus firmus, a fragment of existing music. At the scale of the city and its regional context, this linear structure presents a compelling conceptual model for natural and cultural equity. (Image courtesy of Matthew Skjonsberg.)

generations, the set of additional rules had become highly nuanced: Consonances were now categorized as perfect or imperfect, and the octave could be subdivided harmonically or arithmetically. The possible movement of simultaneous voices in relation to one another was carefully categorized into three types of motion-direct motion (two lines moving parallel), contrary motion (two lines moving in opposite, mirrored fashion), and oblique motion (one line moving while another remains stationary) — and the use of these motions was likewise determined by a set of rules relating perfect and imperfect consonances (Fux 1971, vii). One of the most interesting rules to have developed throughout this process, insofar as it provides a direct connection back to contemporary architectural discourse, is the use of the cantus firmus as the basis for contrapuntal composition. A cantus firmus (fixed song) is an existing melody taken from elsewhere and used as the basis for the composition with each additional voice composed fundamentally in relation to it and in relation to one another. It becomes the site of interpretation, the terra firma of the composition, as it were, making the entire compositional procedure explicitly contextual and interpretive (see Figure 12.4).

\subsection{HOW TO THINK CONTRAPUNTALLY}

Discussing the contemporary relevance of contrapuntal composition, concert pianist and music scholar Rosalyn Tureck (1914-2003) asserted that its foremost feature was as a conceptual model, maintaining that there was a deep conceptual correlation in Bach's music between sound wave periodicity, ornamental figurations, melodic and rhythmic phrasing, and the overall harmonic structure of his compositions (Tureck 2000). So fascinated was she by this correlation that she made it the subject of her lifelong research and founded a series of research societies dedicated to disciplinary interaction about the subject. Among her noteworthy collaborators were evolutionary biologist Stephen Jay Gould, physicist Roger Penrose, and mathematician Benoit Mandelbrot, whose fractal geometry had by then emerged as the go-to analogy for understanding principles of self-similarity in the new age of complexity. In response to a paper called The Fractal Geometry of Music (Hsu and Hsu 1990), in which a series of fractal metaphors were suggested to exist in the music of Bach, Tureck penned a detailed response nearly as long as the 
article itself. "I am delighted to see the interest in the deeper levels of musical composition," she wrote, "... However the article sets down assumptions and conclusions about musical structure which are not only based in subjective interpretation but also contain sweeping blanket statements which cancel out any possibility of the validity of their claims ... Bach was clearly not concerned with fractal relations and fractal theories. The fact that the authors find a 'significant deviation' simply demonstrates the fact that their theories are ... artificially created. 'Deviations' are a very convenient way for excusing the inapplicability of a theory. This is not to say that the possibility of analysis of music in terms of Mandelbrot's theories is impossible." She finally concludes, "If one is looking for the fractal geometry of music, which I applaud wholeheartedly, then the steps taken must be based on something immeasurably more solid and accurate than what appears in this article" (Tureck 1990). For Tureck, the most promising contrapuntal analogies were fundamentally conceptual, having to do with insights obtained by what she described as contrapuntal thinking rather than by attempts to force analogies into a theory after the fact.

In her opening editorial essay for the first volume of INTERACTION_Journal of the Tureck Bach Research Foundation, she writes, "'Interdisciplinary,' 'intercommunicative,' 'interface,' and 'interpersonal' are the guiding icons in the currents of contemporary thought. These constitute varied facets of interaction. The assembly of essays on areas such as physics, mathematics and music, conventionally regarded as disparate, must speak for itself on the platform of interaction ... we have [long] known that there is a correspondence between sound waves and arithmetic. But composed music is more than wavelengths, vibrations, and number. It partakes of, indeed its very essence is dependent upon, processes of thought, form and structure. These processes are abstract; they have to do with mental concepts, not aural activities. They are not technological realizations, nor is their reception limited to physiological, aural responses and emotional, imaginative experience. The abstract processes that create music underlie the acts of musical creativity and performance, which also affect levels of both conscious and unconscious experience in reception. Abstract realms of concept, form and structure are not the sole possession of the sciences. The powerful impact of ... the arts and the sensuous blandishments emanating from the tools of the musical art tend to overshadow the abstract concepts and processes underlying them and from which their forms emerge ... On the other side of the coin, the materialistic thinking that characterizes recent centuries and which has so blatantly crescendoed in our own past century, has emphasized materials, technological tools, and specialized methodologies as prime movers over and above abstract concepts and processes" (Tureck 1997).

In her scholarship, Tureck focused on identifying the characteristics of contrapuntal thinking on the basis of what could be found in the music itself. In the preface to her three-volume An Introduction to the Performance of Bach, she writes, "... the interpretive suggestions are founded on deep principles which grow out of the music itself" (Tureck 1960a, 3). Book II features a chapter with the compelling title "How to Think Contrapuntally," in which she explains, "By contrapuntal thinking I mean the following: firstly, the ability to think simultaneously in two or more 
parts; secondly, the ability to envisage motives continually shifting in the parts; and thirdly, the ability to preserve the relation of the parts to each other successively as well" (Tureck 1960b, 11). Throughout the three volumes, she returns to this theme, giving special emphasis to the relationship between ornamentation and structureoften describing the nature of this relationship using terms such as "integral" and "organic." "The term 'ornamentation' gives the impression, to the modern mind particularly, of something extraneous and dispensable. In the music of Bach and his predecessors this is quite wrong. The first point to learn about ornamentation is that for this music it is indispensable, and the second is that it is as much a part of the musical structure as the printed notes" (Tureck 1960a, 7). Under the heading of "structure," she writes, "Ornaments always are and must be conceived as an intrinsic part of the structure ..." (Tureck 1960a, 8).

Familiar as she was with his work, we should not be surprised by how much Tureck's characterization has in common with Frank Lloyd Wright's conception of ornament as structural expression, which he, in turn, relates first to nature and then to the contrapuntal music of Beethoven: "Integral ornament is simply structurepattern made visibly articulate and seen in the building as it is seen articulate in the structure of trees or a lily of the fields. It is the expression of the inner rhythm of Form ... What I am here calling integral ornament is founded upon the same organic simplicities as Beethoven's Fifth Symphony, that amazing revolution in tumult and splendor of sound built on four tones based upon a rhythm a child could play on the piano with one finger. Supreme imagination reared the four repeated tones, simple rhythms, into a great symphonic poem that is probably the noblest thought-built edifice in our world. And architecture is like music in this capacity for the symphony" (Wright 2005, 347-348). Of course, Wright was likely introduced to the idea of integral ornament through his mentor Louis Sullivan, for whom this ornament was nothing less than a bridge between nature and science, between the organic and the inorganic. Oscillating between the conceptual lens of the musical analogy and that of the biological analogy, Wright later described his ambition to develop this idea of integral ornament into more than a metaphor, making it the basis of the architectural plan itself: "But now, why not the larger application in the structure of the building itself in this sense? Why a principle working in the part if not living in the whole? If form really followed function ... why not throw away the implications of post or upright and beam or horizontal entirely? ... Now why not let walls, ceilings, floors become seen as component parts of each other, their surfaces flowing into each other. To get continuity in the whole, eliminating all constructed features just as [Sullivan] had eliminated [planar] background in his ornament in favor of an integral sense of the whole. Here the promotion of an idea from the material to the spiritual plane began to have consequences. Conceive now that an entire building might grow up out of conditions as a plant grows up out of the soil" (Wright 2005, 146-147).

\subsection{CONTRAPUNTAL LANDSCAPES}

The title of Reyner Banham's Architecture of the Well-Tempered Environment is an allusion to J. S. Bach's 48 Preludes and Fugues of The Well-Tempered Clavier 
(so called in reference to "well-tempered" tuning, an innovation enabling modulation between all major and minor keys) although it contains no references to counterpoint-or even to Bach, for that matter. But there are dozens of references to Wright's buildings, illustrating in detail the advanced integration of structural design, heating and cooling systems, lighting, passive ventilation, and solar design - now early examples of the performative synthesis of architecture and environmental context (Banham 1984). Wright's telling observations about Sullivan's ornament can also be seen as having informed his conception of architecture as the attenuation of latent qualities as potentials already existing in the landscape. In reference to his regional-scale project, Broadacre City (1932-1958), he described this contextual approach as follows: “... the ground itself predetermines all features; the climate modifies them; available means limit them; function shapes them" (Wright 1935). This active regard for context results in a contrapuntal interplay between architectural and topographic form-as is brilliantly

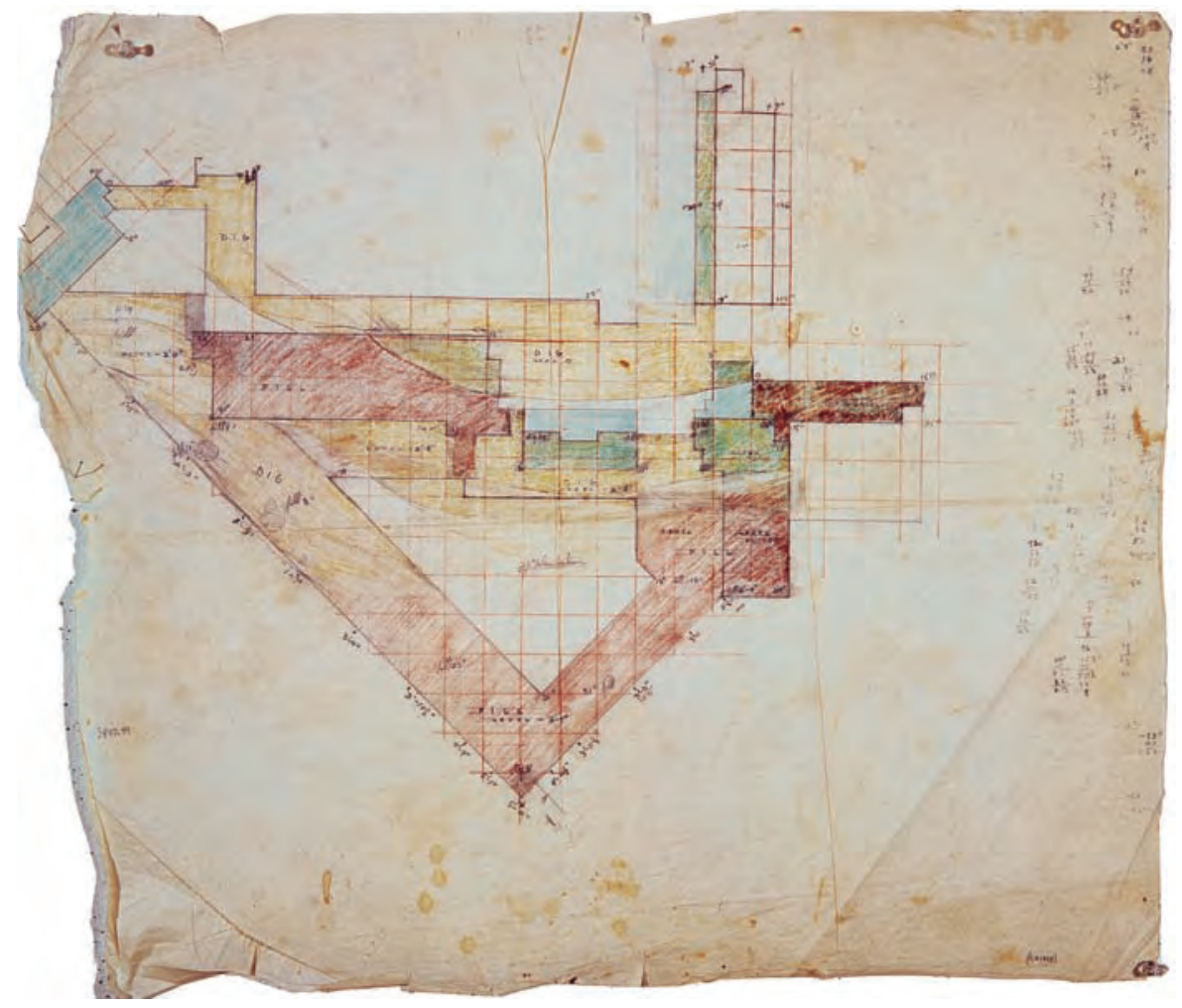

FIGURE 12.5 Taliesin West—cut and fill, 1937. Frank Lloyd Wright's cut and fill drawing for Taliesin West $(\mathrm{gold}=\mathrm{cut} / \mathrm{red}=\mathrm{fill})$ was established so as to incorporate as much material as was excavated-designing for neutral cut and fill, a kind of on-site periodicity. (Image courtesy of The Frank Lloyd Wright Foundation Archives, The Museum of Modern Art, Avery Architectural \& Fine Arts Library, Columbia University, New York.) 
illustrated by the cut and fill diagram Wright himself drew for Taliesin West (see Figure 12.5).

This exemplifies one practical architectural application of the musical analogyboth the origin and destination of displaced materials are anticipated in the design process, acknowledging, as was stated earlier, that architecture is composed by the displacement of other things. At Taliesin West, proximity of material to building was immediate: Earth cut from one part of the site was used to fill another, and the building itself was built of sand from the seasonal river "washes" and stones found on site. Similarly, Wright's designs are typically composed so as to purposefully heighten the sense of security on one hand-often earth-integrated, backed into the site's topography through such cut and fill procedures as described previously_and the sense of freedom on the other-sheltered spaces facing onto broad elevated terraces with panoramic views. Thus, the relevance of aesthetics to what might appear a functionalist method can again be discerned by looking to the Greek etymology of the term, aesthesis ( $\alpha i \theta^{\prime} \theta \eta \sigma 1 \varsigma$ ), which pertains cumulatively to our senses - the sensory organs of sight, sound, smell, touch, and taste as well as to our cognitive sensibilities, including those of justice, well-being, and harmony.

Therefore, a contrapuntal design process involves composing designs in relation to their apparent opposite and begins by identifying the cantus firmus-the stable, underlying ecological structure to which the design must respond and defer and the social realities that design represents performatively and symbolically. At the scale of the city, the initial steps of such design-analysis could be (a) Identify Natural Landscape Systems, (b) Identify Void Design to Be Retained, (c) Identify Cultural Landscape Systems, (d) Ascertain Natural and Cultural Boundaries, and (e) Ascertain Natural and Cultural Intersections. By emphasizing the fundamental priority of continuity in existing ecological and social systems, regional design methods such as Phil Lewis' approach to determining "where not to build" set the stage for design as an interpretation of such contextual analysis (see Figure 12.6) (Lewis 1996; note: also see Manuel Schweiger's Chapter 15 in this book).

The contrapuntal application of Lewis' methods can be seen in Arup's ongoing sustainability master plan for the city of Addis Ababa, which correlates rural mobility and urban river corridors and is predicated on the recognition that soils in the region have been severely depleted due largely to subsidization policies that have displaced traditional pastoralists in favor of intensive ranching methods (see Figure 12.7).

By strategically prioritizing soil and water management along with mobility throughout the city for pastoralists, the scheme demonstrates how, by turning away from notions of self-sufficiency, both rural and urban districts can benefit from the contextual composition of natural and cultural infrastructural systems.

Likewise, West 8's topographically and hydrologically proactive design for the Tulsa Riverfront addresses a site that links rural and urban districts by making the landscape itself a visual and atmospheric register of seasonal water levels (see Figure 12.8).

Restoring soils and disrupted hydrological flows, terraced retention basins yield water levels that can be read at a glance, communicating seasonal variability to 


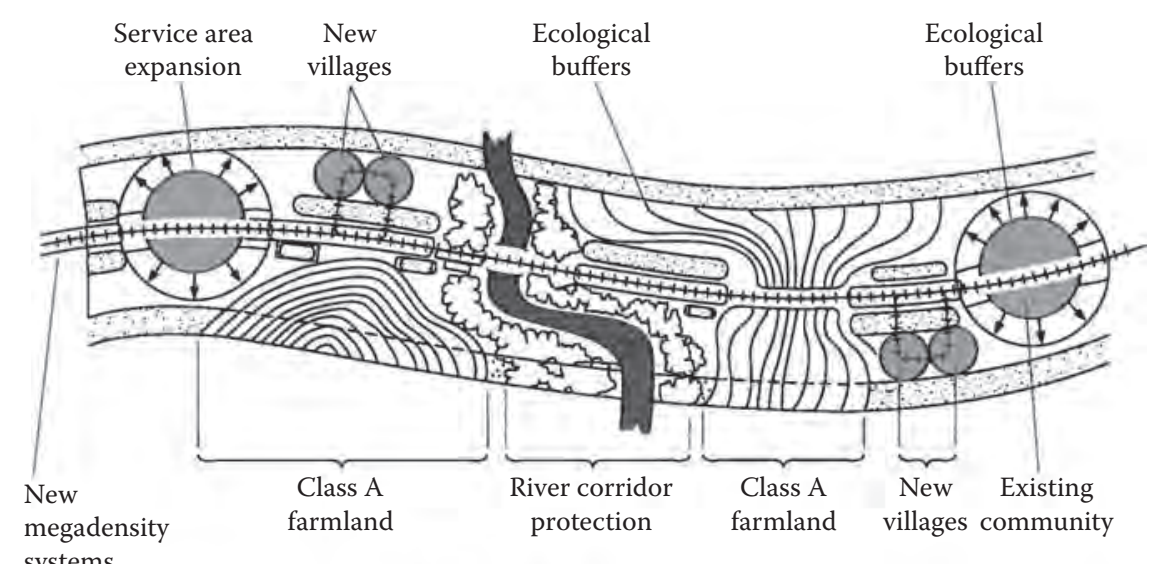

systems
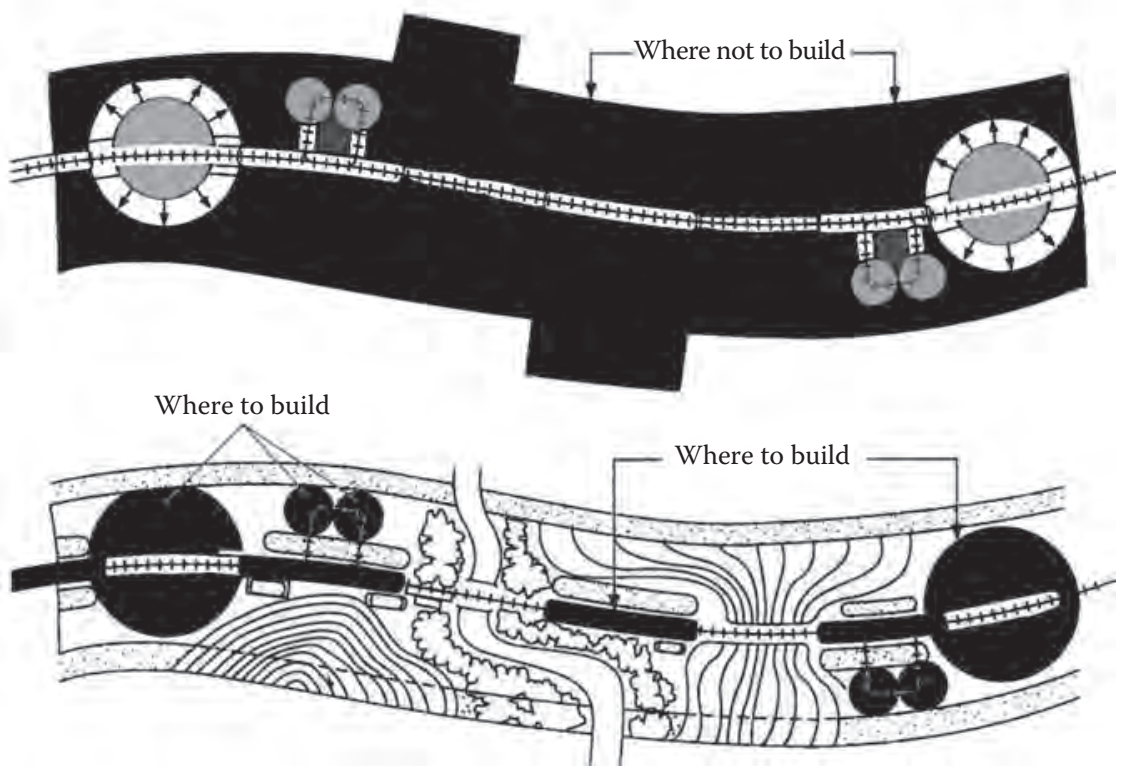

FIGURE 12.6 Where not to build. Phil Lewis, FASLA, outlines a nine-step method, prioritizing existing natural and cultural conditions on site-i.e., river corridor protection, Class A farmland, existing communities, etc.- - resulting in a circumscribed footprint for development. (Image courtesy of Matthew Skjonsberg with Phil Lewis, FASLA.)

highway commuters and creating a variety of new water landscapes and habitats experienced by park visitors as visually distinct from one visit to the next. While these terraced ponds might be regarded as superficial—even sentimental—they are, in reality, integral ornament, a structural expression of the functional dynamics of the site as second nature (see Figure 12.9). 


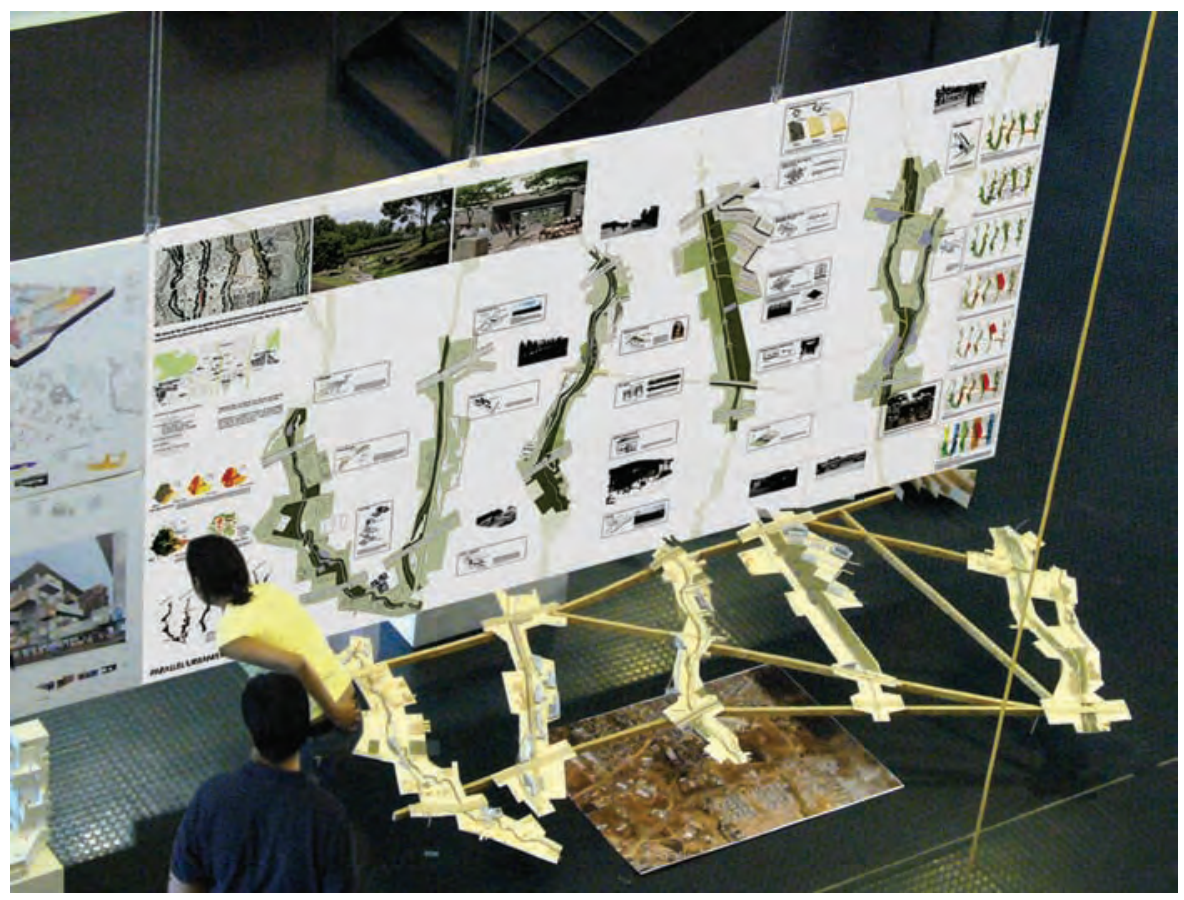

FIGURE 12.7 Parallel urbanism-Addis Ababa, Ethiopia, 2007. Addressing the strategic decentralization of cattle markets by locating them along a latent natural corridor network, the design relates both rural and urban interests and simultaneously creates safe mobility corridors, addresses erosion in the rivers and streams, improves water quality and access, and triggers public spaces with functional benefit to both adjacent and temporal parties. Initiated as a project with Prof. Marc Angélil at ETH-Zurich, it has since been taken up by Arup as the basis for the sustainability master plan they are preparing for the City of Addis Ababa. (Image courtesy of Matthew Skjonsberg with Sebastian Alfaro Fuscaldo and Noboru Kawagishi.)

Another of West 8's projects, Happy Isles, takes this contrapuntal logic to its extreme: the creation of a series of new, sprayed-up sand islands to mitigate storm surges off the coast of Belgium and The Netherlands. Located beyond the curve of the horizon $10-20 \mathrm{~km}$ from shore-and therefore not visible from the existing coastthese dune islands, measuring up to $1500 \mathrm{~km}^{2}$, will break the increasing waves while creating new underwater habitats and respecting current sea transportation routes. As a further precaution, ingenious engineering of underwater topography causes offshore undertow to draw down the sea level at the existing coast during northwestern storms. Together with Magnus Larsson's project for artificial linear dunes to stop the accelerated expansion of the Sahara, the project indicates how infrastructural design can employ contrapuntal thinking in response to the polar phenomena of climate change: sea-level rise and desertification (see Figures 12.10, 12.11, and 12.12). 


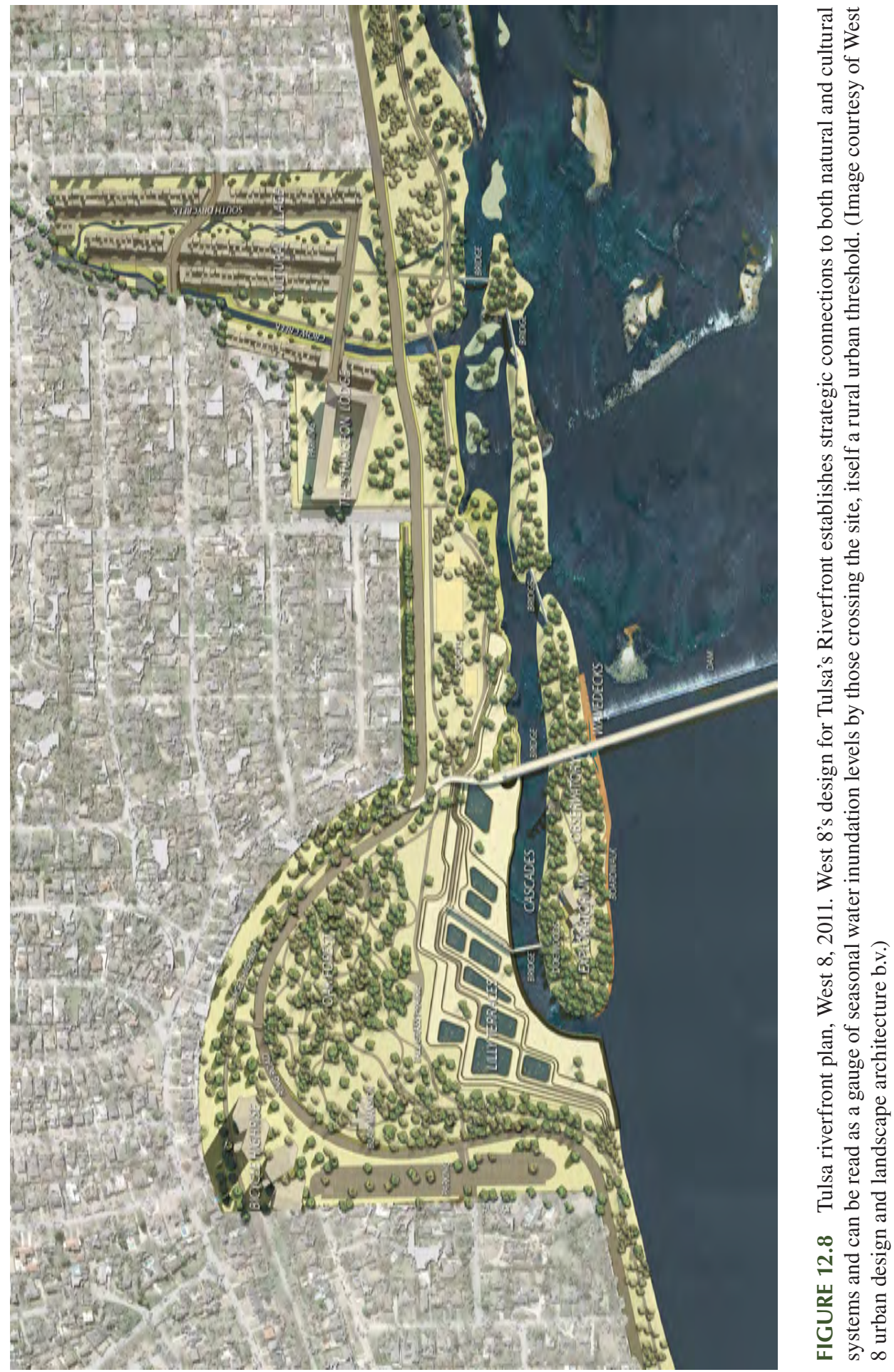




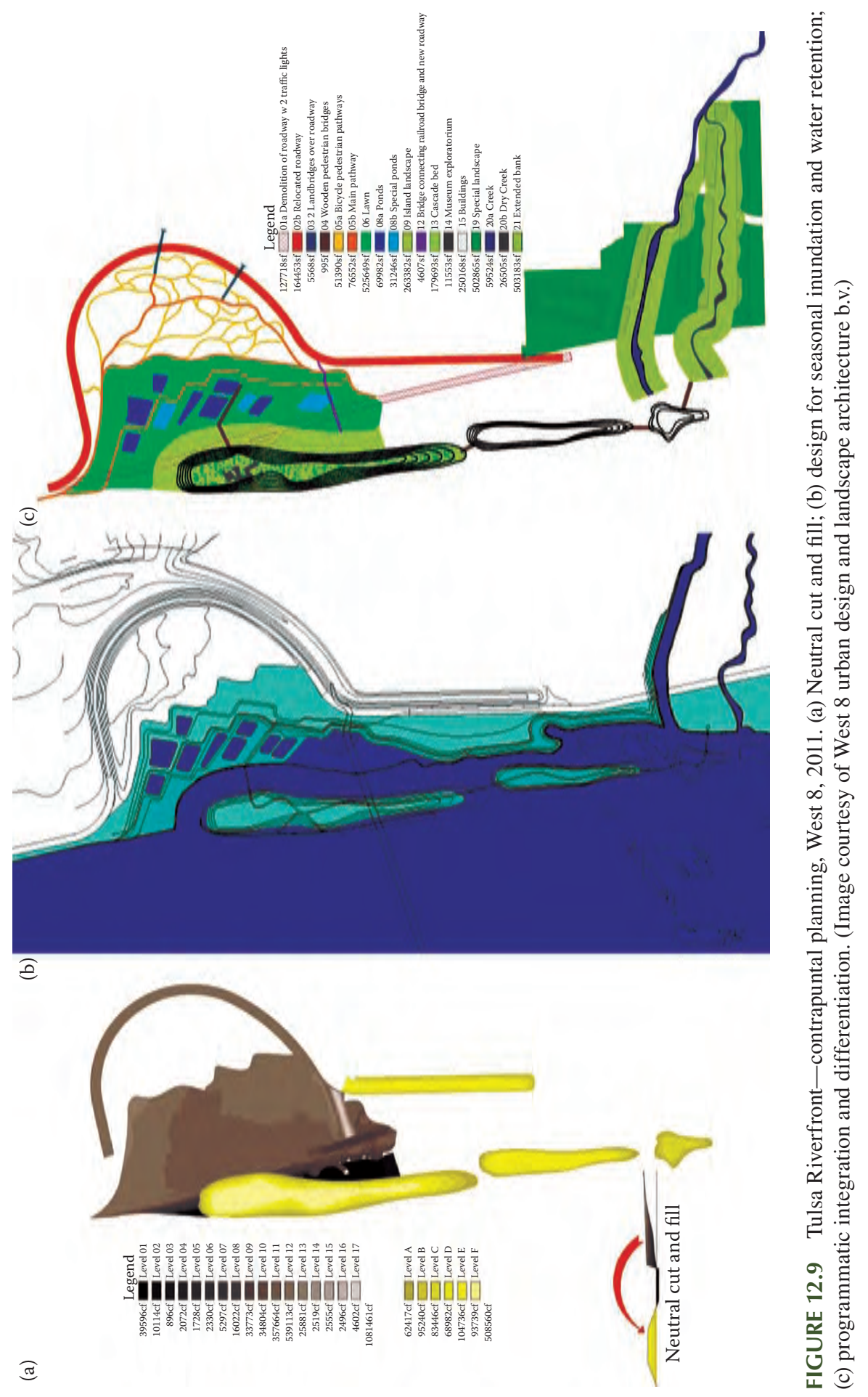



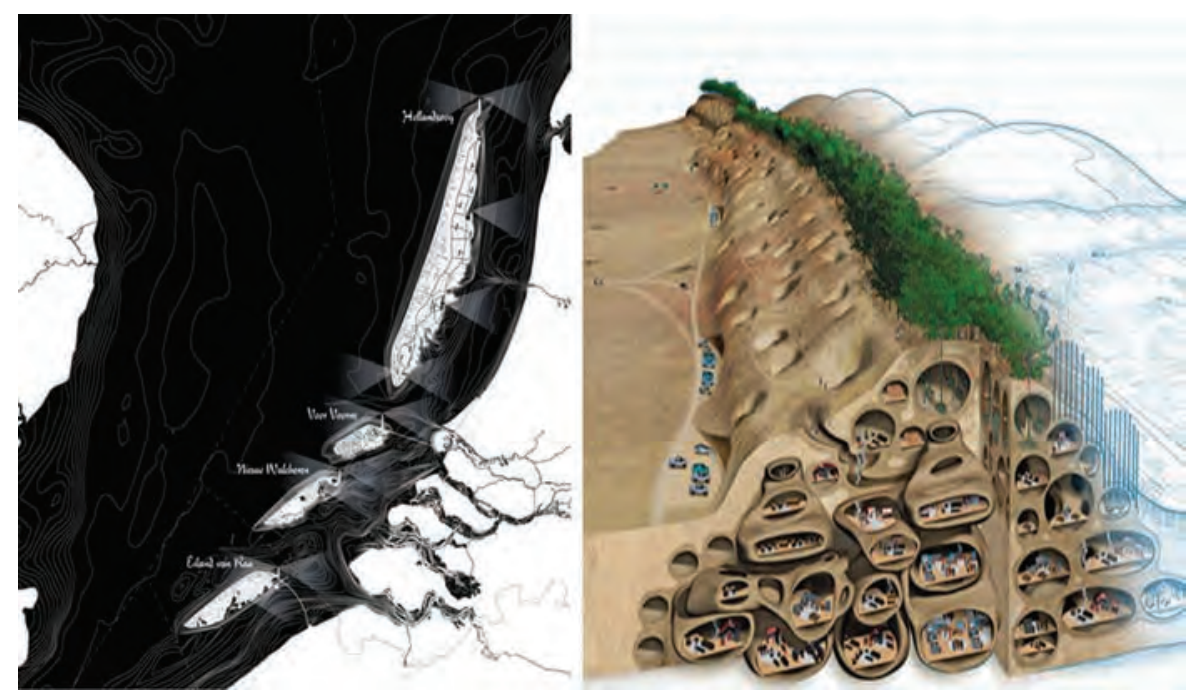

FIGURE 12.10 Regional-scale periodicity-West 8, Happy Islands: Belgium, Dutch, and Flemish Coast, 2006; Magnus Larsson, Dune: Transcontinental Africa, 2008. Along with rural-urban dynamics, climate change-induced sea-level rise and desertification are also examples of periodic phenomena. These two strategies represent attempts to address sealevel rise and desertification as polar effects of climate change to retain currently inhabited regions. An alternate, lowest-risk version of this initiative would be to establish "safe zones" on the basis of those areas of the world least affected by climate change. (Image courtesy of (left) West 8 urban design and landscape architecture b.v. (right) Magnus Larsson.)
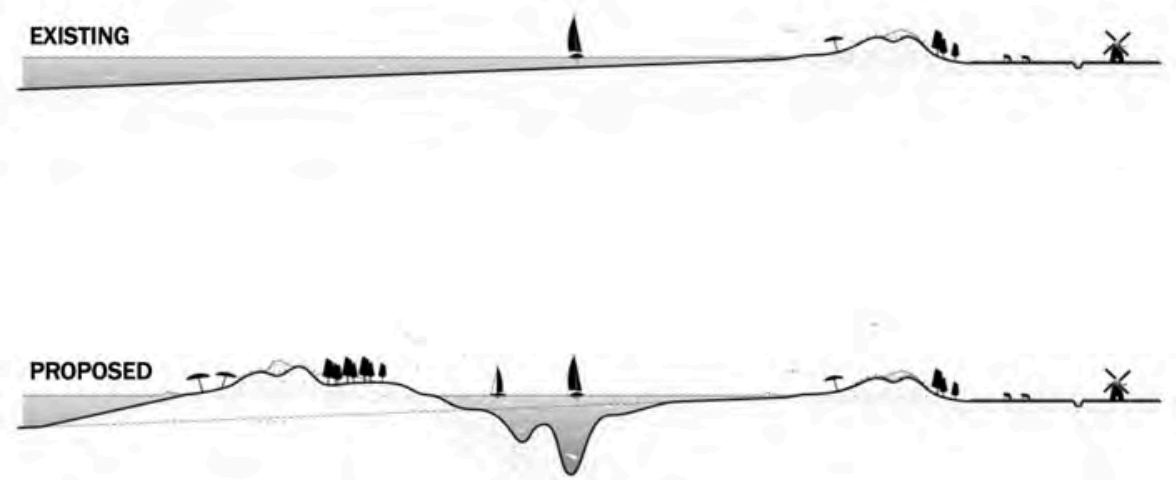

FIGURE 12.11 Happy Islands-cut and fill, West 8, 2006. The creation of the islands is made possible by a massive cut-and-fill operation, yielding protective barrier islands and its counterpart: an inland sea, whose terraced underwater contours provide varied habitats for ecological diversity in contrast to the existing, relatively monocultural condition. (Image courtesy of West 8 urban design and landscape architecture b.v.) 


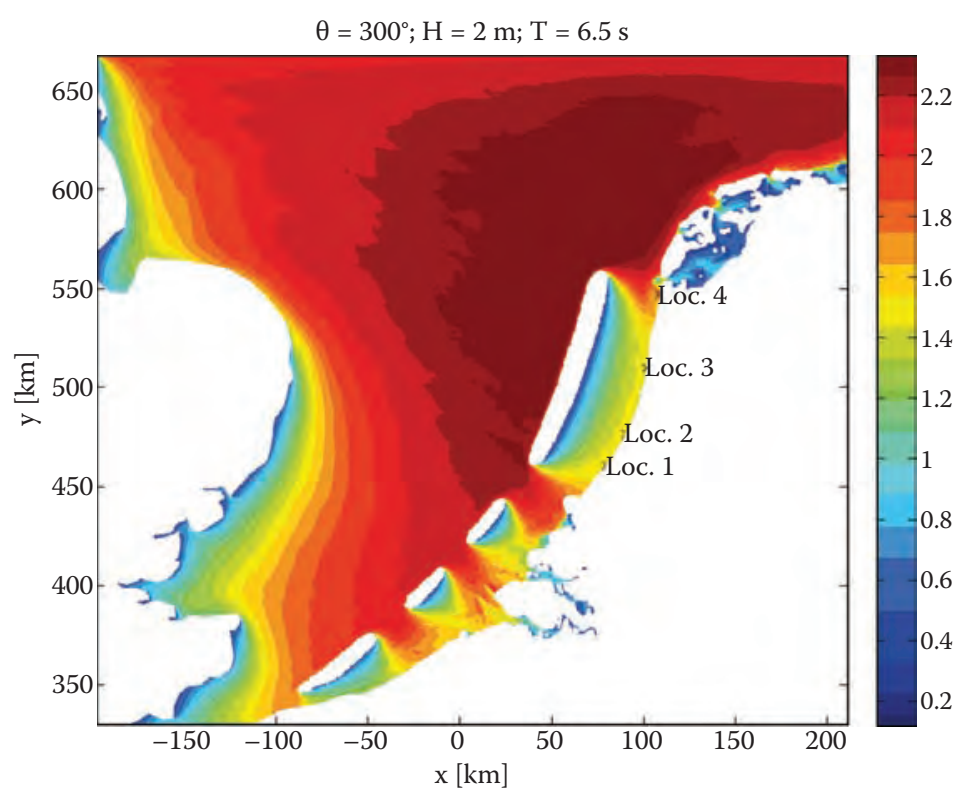

FIGURE 12.12 Happy Islands-as storm surge protection, West 8, 2006. These dune islands, measuring up to 150,000 hectares in size, will break increasing storm surge waves. Also, due to ingenious engineering of the gullies, the offshore undertow will cause the sea level to drop during northwestern storms. (Image courtesy of West 8 urban design and landscape architecture b.v.)

\subsection{CONCLUSION}

In his final year, Louis Sullivan (1856-1924) drew an esoteric series of graphic abstractions illustrating "organic" and "inorganic" forces, representing natural forces with curved lines and human forces with straight ones, writing, "These two elements ... are not to be considered separate conceptions to be harmonized, but as two phases" (Sullivan 1967). Again, this periodic concept can be attributed to Pythagoras, who saw the circle as related to the circuits of stars and planets and the square represented the physical world and human rationality, and to his contemporary, Heraclitus (535-475 B.C.), who conceived of the "unity of opposites," which led to the pedagogical tradition of coincidentia oppositorum, in which the coexistence of opposites are understood as creating productive tension. Vitruvius later developed this concept in his architecture, and Da Vinci's Vitruvian Man memorably illustrates the conceptual model of dual geometries and the aspiration to synthesize artistic and scientific knowledge. Taken together, in the tradition of coincidentia oppositorum, musical and biological analogies can invigorate and clarify one another-providing a grammar of contextual relationships to complement the discipline's dedication to the computational-empirical-managerial lexicon.

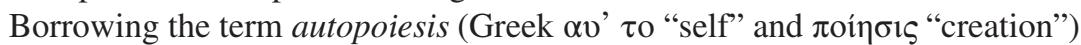
from the emerging field of chronobiology—which examines periodic phenomena in living 
organisms and their adaptation to solar and lunar rhythms-Patrick Schumacher concludes volume one of The Autopoiesis of Architecture with the statement, "... one might talk about an artificial ecology ... not only can parameters be shifted out of natural ranges but wholly new, artificial forces and their ... laws and logics might be defined ... An artificial, second nature can be conjured via scripted, quasinatural laws, rich in internal resonances, as well as inter-articulations with external contexts" (Schumacher 2011). This last comment indicates how contrapuntal thinking can meaningfully oppose contemporary interpretations of the biological analogy, which curiously enough tend to go along with arguments for self-sufficient cities, the autonomy of architecture, and architectural autopoiesis-as though second nature could be conceived of as independent from nature itself. The opposite of autopoiesis, a closed process in which context might be an afterthought, is allopoiesis: the process whereby an organizationally open system produces something other than itself-as, for example, in an assembly line, on which each participant contributes a part to a synthetic whole. It is clear that cities are, in reality, allopoietic rather than autopoietic; they are the cumulative result of the contributions of diverse actors, none of whom are solely in control. This brings us back to Terzidis' distinction between design and planning: Until now the arguments for analogical thinking have been made from the standpoint of the designer's conceptualization of urban form and its relationship to context. Turning finally to planning, the analogy of contrapuntal thinking - concerning itself with multiple voices and a contextual cantus firmus - anticipates the allopoietic reality of cities and lends itself to open planning processes involving inputs from diverse actors. The projects illustrated here also represent sincere efforts in this direction, acknowledging the form of the city as fundamentally open-ended and resulting from an ongoing dialogue among its citizens-often despite resistance from the planning authorities involved. In The Voice of Liberal Learning, Michael Oakeshott expresses a sympathetic attitude regarding education itself: "The pursuit of learning is not a race ... it is not even an argument or symposium: it is a conversation. A conversation ... has no predetermined course ... and we do not judge its excellence by its conclusion; it has no conclusion, it is always put by for another day. Its integration is not superimposed but springs from the quality of the voices which speak, and its value lies in the impressions it leaves behind in the minds of those who participate" (Oakeshott 1989).

Whatever designs are made, what really counts is how those who inhabit the city will think of it, describe it to one another, and participate in it. To this end, the relational nature of analogical thinking goes a long way toward involving the public in the design and planning processes. Just so, as an established, historic alternative to prevalent contemporary notions of self-sufficiency, contrapuntal thinking provides a promising conceptual framework for the design and planning of rural urban dynamics capable of giving contradictory interests and polemical aims relational, aesthetic formal expression with enduring cultural value. 


\section{REFERENCES}

Alberti, L. B. (1965). Ten Books on Architecture, ed. by Joseph Rykwert as a complete reprint from the 1755 edition. London: Tiranti.

Banham, R. (1984). Architecture of the Well-Tempered Environment. 2nd ed. Chicago: University of Chicago Press.

Cicero, M. T. (2008). The Nature of the Gods, New York: Oxford University Press.

Cronon, W. (1991). Nature's Metropolis. New York: W.W. Norton.

de Beldomandi, P. (1984). Contrapunctus, ed. Jan W. Herlinger. Lincoln: University of Nebraska Press.

Fux, J. (1971). ed: Mann, Alfred, Gradus Ad Parnassum. New York: W.W. Norton.

Hsu, K. and A. Hsu (1990). Fractal geometry of music, Proceedings of the National Academy of Science, Vol. 87, pp. 938-941.

Margulis, L. (2010). eds. Brouwer, Mulder, The basic unit of life; Politics of the Impure, Rotterdam: NAI.

Oakeshott, M. (1989). ed. T. Fuller, The Voice of Liberal Learning: Michael Oakeshott on Education, New Haven: Yale University Press.

Ortega y Gassett, J. (1962). Man and Crisis, New York: W.W. Norton.

Plato (1981). Timaeus. ed: Cornford, Francis MacDonald. New York: MacMillan.

Sayer, A. (2010). Method in Social Science: A Realist Approach. Revised 2nd ed. New York: Routledge.

Schumacher, P. (2011). The Autopoiesis of Architecture: A New Framework for Architecture. Vol.1. Chicago: Wiley.

Sennett, R. (1992). The Fall of Public Man, New York: W.W. Norton.

Sherman, G. (2010). GSD Throwdown: Battle for the Intellectual Territory of a Sustainable Urbanism. Available at http://urbanomnibus.net/2010/11/gsd-throwdown-battle-for-theintellectual-territory-of-a-sustainable-urbanism/ (accessed November 8, 2012).

Skjonsberg, M. (2013). eds. Farini, Nijhuis, Hidden rivers: Addis Ababa's rural urban metabolism, Flowscapes: Exploring Landscape Infrastructures, Madrid: Universidad Francisco De Vitoria.

Steadman, P. (2008). The Evolution of Designs: Biological Analogy in Architecture and the Applied Arts, London: Routledge.

Sullivan, L. (1967). A System of Architectural Ornament According with a Philosophy of Man's Powers. New York: Eakins Press.

Taylor, N. (2007). Urban Planning Theory since 1945, London: Sage.

Terzidis, K. (2007). The Etymology of Design: Pre-Socratic Perspective; Massachusetts Institute of Technology; Design Issues, Autumn 2007, Vol. 23, No. 4, p. 69; Posted Online October 5, 2007.

Tureck, R. (1960a). An Introduction to the Performance of Bach, Book I, London: Oxford University Press.

Tureck, R. (1960b). An Introduction to the Performance of Bach, Book II, London: Oxford University Press.

Tureck, R. (1990). Unpublished letter.

Tureck, R. (1997). Interaction, Journal of the Tureck Bach Research Foundation. Vol.1. London: Oxford University Press.

Tureck, R. (2000). In conversation with author.

von Thünen, J. H. (1966). An Isolated State. New York: Pergamon Press.

Wright, F. L. (1935). Broadacre City: A new community plan. Architectural Record, April 1935.

Wright, F. L. (1949). Genius and the Mobocracy. New York: Duell, Sloan and Pearce.

Wright, F. L. (2005). An Autobiography. 3rd ed. Petaluma: Pomegranate. 